\title{
Comparison of Graft Survival between Fat Harvested from Abdomen and Medial Thigh for Facial Contour Deformity: A Randomised Control Trial
}

\author{
Shohreh Ahmadi1, Abdul Malik Mujahid1, Husnain Khan², Farrukh Aslam Khalid1, Muhammad Saleem¹ and
} Muhammad Younas Mehrose ${ }^{1}$

\begin{abstract}
Objective: To compare the graft survival between fat harvested from abdomen and medial thigh for facial contour deformity.

Study Design: Randomised control trial (RCT)

Place and Duration of Study: Jinnah Burn and Reconstructive Surgery Center, Lahore, from October 2015 to April 2017. Methodology: Patients fulfilling the inclusion criteria were randomly divided into two groups. Fat was harvested from medial thigh in Group A and from abdomen in Group B. Outcome was measured in terms of fat survival by comparing mean fat at baseline, first and $12^{\text {th }}$ week. Final fat survival thickness $\geq 6.00 \mathrm{~mm}$ at $12^{\text {th }}$ week was considered as excellent. ANOVA was used for comparison of mean fat thickness $(\mathrm{mm})$ between the groups, and Chi-square test for outcome and complications among groups with $p$-value $<0.05$ as statistical significance.

Results: Mean age of subjects was $27 \pm 7.44$ (range 12 to 60 ) years. Mean final fat thickness in Group A was 6.030 $\pm 0.095 \mathrm{~mm}$ and in Group B was $4.989 \pm 0.094 \mathrm{~mm}(\mathrm{p}=0.001)$. Thirty patients $(76.9 \%)$ in Group A and none in Group B showed excellent response $(p=0.001)$.

Conclusion: Outcome of graft survival with fat harvested from medial thigh was better as compared to that from abdominal fat.
\end{abstract}

Key Words: Fat injection, Fat grafting, Romberg disease, Fat survival, Donor site, Graft survival.

\section{INTRODUCTION}

Contour defects after the trauma, burns, Romberg disease, congenital problems or ablative surgery are common causes of facial asymmetry. Many traditional reconstructive options are utilized for restoration of facial contours like dermal fat grafting, fat transfer and use of synthetic material like silicone implants and hydroxyapatite implants. The pioneer of fat grafting used fat graft as facial filler for correction of facial contour defects. ${ }^{1}$ Several studies reported a high resorption rate after lipofilling.2,3 Peer et al. explained the fact that the survivability of transplanted fat cell correlates to the volume of fat cells transplanted. ${ }^{4}$ With the advent of liposuction in 1980s, Coleman technique resulted in the increased survival of fat attributed to gentle extraction, handling, preparation and transfer with excellent long term results. 5

${ }^{1}$ Department of Plastic Surgery, Jinnah Burn and Reconstructive Surgery Centre / Allama Iqbal Medical College, Lahore, Pakistan

2 Department of Plastic Surgery, Holy Family Hospital, Lahore, Pakistan

Correspondence: Dr. Abdul Malik Mujahid, Department of

Plastic Surgery, Jinnah Burn and Reconstructive Surgery

Centre / Allama Iqbal Medical College, Lahore, Pakistan

E-mail: iqbalian_127@yahoo.com

Received: March 29, 2018; Accepted: December 4, 2018
Fat grafting is done either alone or in combination with other rejuvenation procedure with advantage of being less invasive procedure with minimal complications. ${ }^{6}$ The advantages of autologous fat grafting are easy availability, ease in harvest, the minimum risk of infection, and the short recovery period. It can be done under local anesthesia as a day case procedure depending upon the area to be injected. It is the procedure of choice for correction of facial contour defect and facial rejuvenation with permanent results. 6

Fat can be harvested from thigh, abdomen, lower back, hip, sacrum and knees, ${ }^{7}$ which may affect the grafting. However, most of these reports are anecdotal record and choice of the donor site and the quality of fat graft harvested has been attributed to greater survival of implanted fat cells. Li et al. compared different donor sites in mice and found no difference in fat survival harvested from either donor site. ${ }^{8}$ In another systemic review by $\mathrm{Yu}$ et al. of autologous fat grafting survival rate and related severe complications, survival rates varied from 34 to $82 \%$ in the breast and $30-83 \%$ in the facial area in mice. ${ }^{9}$

The authors hypothesised that the choice of the donor site between abdomen and medial thigh has no bearing on fat survival for facial contour deformity. The aim of this study was to compare the survival outcome of fat injection with thigh and abdominal fat using high frequency ultrasonography for evaluation of outcome. 


\section{METHODOLOGY}

A randomized controlled trial was conducted at Jinnah Burn and Reconstructive Surgery Center, Lahore, from October 2015 to April 2017. Sample size was calculated using win-pepi ver: 11.15 with significance level of $5 \%$ and power of study $80 \%$. After approval from Ethical Committee of Hospital and Trial Registration, 78 subjects with facial contour deformity, aged 10-60 years, congenital/post Romberg disease/post traumatic facial deformity, and no comorbidity, were selected through purposive sampling. Patients with diabetes mellitus, ischemic heart disease, and bleeding disorders were excluded from study. Subjects were randomised into two groups (39 in each group) by using balloting method by researcher. After an informed consent, preoperative high frequency ultrasonography was done to evaluate subcutaneous tissue (fat) thickness. Preoperative standard photographs with anto-posterior, oblique and 45 degree angle views were taken for comparison. The fat was harvested from medial thigh in Group A and from the abdomen in Group B, prepared with the help of gravity and injected with $10 \mathrm{cc}$ syringe (14G needle) in multiple layers under local anesthesia. Then 20-30\% over-correction was done because of chance of absorption.

Postoperative high frequency ultrasonography (18 MHz) for subcutaneous tissue thickness was performed to compare the fat survival in each group at 3 months. Outcome was classified as excellent (6 $\mathrm{mm}$ or more), good $(5-6 \mathrm{~mm})$ and fair (less than $5 \mathrm{~mm}$ ) on the basis of final fat graft survival. Complications like bruising, pain, seroma and bleeding were compared in two groups.

Data was entered and analysed in SPSS Version 20.0. Frequencies and percentages were calculated for qualitative variables like gender, graft survival, and outcome of graft. Mean and standard deviations were calculated for numerical variables like age, thickness of graft at base line, 1-week and 12-week. ANOVA test was used to compare the mean thickness and Chi-square test was used to compare the outcomes between two groups with $p \leq 0.05$ as statistical significance.

\section{RESULTS}

A total of 78 patients were included in the study. The mean age of subjects was $27 \pm 7.44$ (range 12 to 60 ) years. Mean preoperative fat thickness in Group A (Medial thigh fat) was $1.612 \pm 0.0767 \mathrm{~mm}$ as shown in
(Figure 1a) and in Group B (Abdominal fat) was 1.605 $\pm 0.0723 \mathrm{~mm}(p=0.650)$ as shown in Figure (2a). Mean final fat thickness in Group A was $6.030 \pm 0.095 \mathrm{~mm}$ as shown in Figure (1c) and in Group B was $4.989 \pm 0.094$

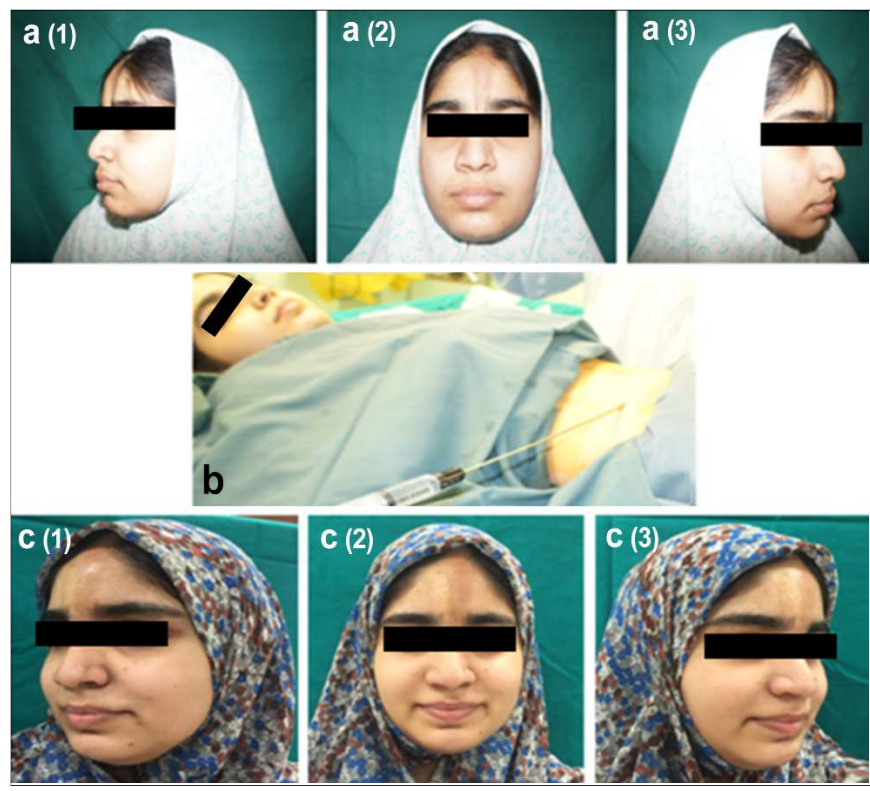

Figure 1: A 21-year female with Romberg disease having forehead lipoatrophy was treated with fat grafting harvesting from abdomen. (a) pre-op views 1. lateral 2. front 3. lateral. (b) perop view. (c) post-op view: 1. lateral 2. front 3. lateral.
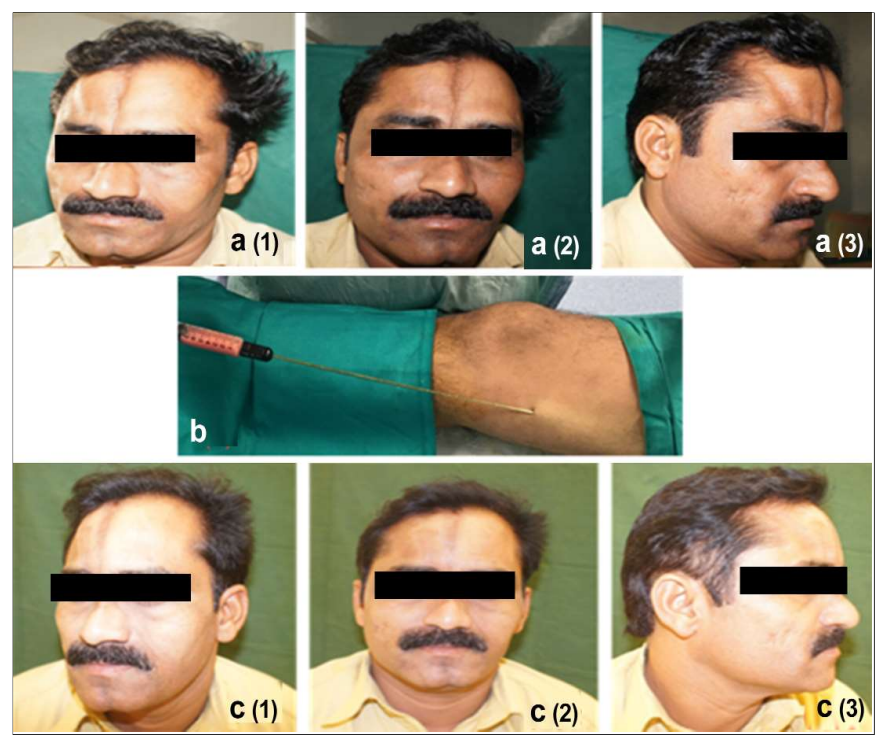

Figure 2: A 38-year male with Romberg disease having post-traumatic forehead lopoatrophy was treated with fat grafting harvested from thigh (a) pre-op view. 1 lateral 2. front. 3 lateral. (b) intra-op view. (c). post-op view after 3 months: 1 . lateral 2 . front 3 . lateral view.

Table I: Fat survival among groups $(n=78)$.

\begin{tabular}{|c|c|c|c|c|c|c|}
\hline Fat thickness & Groups & Mean & Std. Deviation & Minimum & Maximum & $\begin{array}{l}\text { ANOVA } \\
p \text {-value }\end{array}$ \\
\hline \multirow[t]{2}{*}{ Fat thickness preoperative $(\mathrm{mm})$} & Group A & 1.6128 & .07671 & 1.50 & 1.70 & .650 \\
\hline & Group B & 1.6051 & .07236 & 1.50 & 1.70 & \\
\hline \multirow[t]{2}{*}{ Fat thickness 1 week } & Group A & 6.6897 & .10953 & 6.50 & 6.80 & .001 \\
\hline & Group B & 5.7641 & .07066 & 5.70 & 5.90 & \\
\hline \multirow[t]{2}{*}{ Fat thickness 12 weeks (final fat thickness) } & Group A & 6.0308 & .09502 & 5.80 & 6.20 & .001 \\
\hline & Group B & 4.9897 & .09402 & 4.80 & 5.10 & \\
\hline
\end{tabular}


Table II: Complications among groups

\begin{tabular}{l|c|c|c|c}
\hline Complications & $\begin{array}{c}\text { Group A } \\
\text { (Medial thigh fat) } \\
\mathrm{n}=39\end{array}$ & $\begin{array}{c}\text { Group B } \\
\text { (Abdomen fat) } \\
\mathrm{n}=39\end{array}$ & $\begin{array}{c}\text { Total } \\
\text { Complication } \\
\mathrm{n}=78\end{array}$ & $\begin{array}{c}\text { Chi-square } \\
\mathrm{p} \text {-value }\end{array}$ \\
\hline Bruising & $7(17.9 \%)$ & $4(10.3 \%)$ & $11(14.1 \%)$ & 0.329 \\
Pain & $6(15.4 \%)$ & $4(10.3 \%)$ & $10(12.8 \%)$ & 0.498 \\
Seroma & $3(7.7 \%)$ & $8(20.5 \%)$ & $11(14.1 \%)$ & 0.104 \\
Bleeding & $1(2.6 \%)$ & $1(2.6 \%)$ & $2(2.6 \%)$ & 1.000 \\
\hline
\end{tabular}

$\mathrm{mm}(\mathrm{p}=0.001$, Figure $2 \mathrm{c}$, Table I). In group A, 76.9\% (30) had excellent response and in group $0.0 \%(0)$ subjects showed excellent response. Nine patients $(23.1 \%)$ in Group A, and $(n=24) 61.5 \%$ in Group B showed good outcome. Fair outcome was observed in $38.5 \%(n=15)$ in Group B ( $p=0.001)$.

In Group $A, 17.9 \%(07)$ had bruising as compared to $10.3 \%(04)$ in group $B(p=0.329)$ and $15.4 \%(06)$ in group A had pain as compared to $10.3 \%$ (04) in group B $(p=0.498)$. Seroma formation occurred in $7.7 \%(03)$ in group $A$ and $20.5 \%(08)$ in group $B(p=0.104)$ and only $2.6 \%(01)$ subject both in group $A$ and $B$ had bleeding at donor areas $(p=1.000$, Table II).

\section{DISCUSSION}

Fat grafting, has been considered as an ideal filling material for the facial asymmetry correction both for the reconstructive and aesthetic purpose. 9 It has also become first choice due to its permanent nature. Coleman studied autologous fat grafts harvested and refined by the Coleman technique, and evaluated the survival of the transferred fat that has long been in debate. The most important factor in fat transfer is its resorption rate, which in his technique varies from 20 to $90 \%$. ${ }^{10,11}$

Many techniques have been proposed for the better survival of the fat. Coleman technique has gained much popularity but long term volume maintenance depends on many factors like the method of harvesting, processing and transfer. The adipose derived stem cells also play an important role in the final outcome as shown by Nguyen and Illouz in their studies. ${ }^{12,13}$

The favourable donor site for fat harvesting is widely debated. Strong et al. in 2015 reviewed harvesting, processing and injection technique from different body parts and found no statistically significant difference in the fat harvest from three different donor sites. ${ }^{14} \mathrm{Li}$ et al. harvested fat from five different commonly used donor sites: inner thigh, outer thigh, upper abdomen, lower abdomen and flanks, and analysed volume, weight and histological markers in their study and found no difference in weight, volume and histological parameters of fat harvested from five different sites. ${ }^{8}$ The results of these studies is contradictory to the results of this study where fat survival was better in the patients with thigh as a donor site and the main positive point in this was more analytical analysis with different histological markers as compared to Li and Strong et al. studies.8,14 Hudson et al. suggested that gluteal-femoral region is a better donor site as the adipose tissue in this region consists of larger fat cells and has more lipogenic activity than abdomen, breast or face.15 In a study by Horel, technique for liposuction fat re-implantation and longterm volume was evaluated by magnetic resonance imaging which found that together with basic clinical observation, magnetic resonance imaging provides an objective evaluation of volume loss with an average error of only $5 \%$, but it is more difficult and more expensive than ultrasonography. ${ }^{16}$ The present study findings were evaluated by ultrasonography with similar outcome evaluated basic clinical observation and use of high frequency ultrasonography with similar results and in concordance with $\mathrm{Kim}$ et al. ${ }^{17} \mathrm{Small}$ et al. in a study for breast reconstruction injected the fat from thighs and abdomen concluded that regardless of volume injected or tissue radiation, did not affect volume retention in fat grafting. ${ }^{18} \mathrm{Ibrahim}$ et al. suggested that fat graft are the natural choice for reconstructive, regenerative and aesthetic surgery but long term studies are needed to assess the stability of the breast after fat grafting found better survival of fat harvested from thighs. ${ }^{19}$

This study evaluated volume loss with ultrasonography and we compared two most commonly used sites as a donor of fat cells i.e. thigh and abdomen to check the preoperative and postoperative thickness of subcutaneous tissue. There is a very significant difference in the mean thickness and the final volume gained in the two groups in this study due to thigh having more number of adipocytes has more longevity as compared to abdomen. This is consistent with the results of Hudson and Simonacci studies, 15,20 who noted significant difference in the complication rates in these two groups. The most common complication seen at the donor site was bruising in $17.9 \%$ of cases in Group A patients. Pain and bleeding was comparable in the two groups.

The one factor limiting the results of this study was the absence of analysing factors like histological parameter. It might be possible that if this parameter was included in the study, the results would have been consistent with the results given in literature. Study results showed that the final outcome depends on the selection of the donor site.

\section{CONCLUSION}

Graft survival with fat harvested from medial thigh has better outcome as compared to abdominal fat.

\section{REFERENCES}

1. Ellenbogen R, Motykie G, Youn A, Svehlak S, Yamini D. Facial reshaping using less invasive methods. Aesthet Surg J 2005; 25:1-9.

2. Coleman SR. Long term survival of fat transplants controlled demonstration. Aesthetic Plast Surg 1995; 19:421-5.

3. Bellini E, Geirco MP, Raposio E. The science behind autologous fat grafting. Ann Med Surg (Lond) 2017; 24:65-6. 
4. Peer LA. Cell survival theory versus replacement theory. Plast Reconstr Surg 1995; 16:161-8.

5. Ellenbogen R. Fat transfer: Current use in practice. Clin Plast Surg 2000; 27:545-56.

6. Vecchio DD, Rohrich R. A classification of clinical fat grafting; Different problems, Different solution. Plast Reconstr Surg 2012; 130:511-22.

7. Dolen U, Cohen JB, Overschmidt B, Tenenbaum MM, Myckatyn TM. Fat grafting with tissue liquefaction technology as an adjunct to breast reconstruction. Aesthetic Plast Surg 2016; 40:854-2.

8. Li K, Gao J, Zhang Z, Li J, Cha P, Liao Y, et al. Selection of donor site for fat grafting and cell isolation. Aesthetic Plast Surg 2013; 37:153-8.

9. Yu NZ, Huang JZ, Zhang H, Wang Y, Wang XJ, Zhao R, et al. A systemic review of autologous fat grafting survival and related severe complications. Chin Med J (Engl) 2015; 128: 1245.

10. Coleman SR. Structural fat grafting: More than permanent filler. Plast Reconstr Surg 2006; 118:108S.

11. Coleman SR. Autologous fat grafts harvested and refined by the Coleman technique: A comparative study. Plast Reconstr Surg 2008; 122:932-7.

12. Nguyen A, Pasyk KA, Bouvier TN, Hassett CA, Argenta LC. Comparative study of survival of autologous adipose tissue taken and transplanted by different techniques. Plast Reconstr Surg 1990; 85:378-86.

13. Illouz YG. Present results of fat injection. Aesthetic Plast Surg 1998; 12:175-81.

14. Strong AL, Cederna PS, Rubin JP, Coleman SR, Levi B. The current state of fat grafting: A review of harvesting, processing and Injection technique. Plast Reconst Surg 2015; 136:897-912.

15. Hudson DA, Lambert EV, Bloch CE. Site selection for fat autotransplantation: Some observations. Aesthetic Plast Surg 1990: 14:195-7.

16. Horel HW, Feller AM, Biemer E. Technique for liposuction by magnetic resonance imaging. Ann Plast Surg 1991; 26:248-58.

17. Kim HY, Jung BK, Lew DH, Lee DW. Autologous fat graft in the reconstructed breast: Fat absorption rate and safety based on sonographic identification. Arch Plast Surg 2014; 41:740-7.

18. Small K, Choi M, Petruolo O, Lee C, Karp N. Aesthetic Surg J 2014, 34:545-50.

19. Ibrahim S, Mossakowska JR, Michalak S. Fat graft - the natural choice for reconstructive, regenerative and aesthetic surgery. Adv Cell Biol 2017; 2017:113-7.

20. Simonacci F, Bertozzi N, Grieco MP, Grignaffini E, Raposio E. Procedure, applications, and outcomes of autologous fat grafting. Ann Med Surg (Lond) 2017; 20:49-60. 